\title{
Human immunodeficiency virus viral markers seroperevalence in first-time healthy blood donors refered to transfusion centers of bushehr province, South of Iran (April 2004 to March 2008)
}

\author{
Hesam oddin Maneshi ${ }^{*}$, Mojtaba Karimi ${ }^{2}$, Shahab Zare ${ }^{1}$, Gholam Reza Hajiani ${ }^{2}$ \\ From $16^{\text {th }}$ International Symposium on HIV and Emerging Infectious Diseases \\ Marseille, France. 24-26 March 2010
}

\section{Background}

AIDS is one of blood-transmitted diseases so that WHO recommends carrying out the HIV screening test on all donated blood samples. In this study we analyzed seroprevalence, demographic and epidemiologic characteristics of positive HIV cases in first time blood donors of Bushehr province.

\section{Methods}

In this cross-sectional study, 66873 first time donors who were referred for blood donation, during 5 years (April2004 to March2008), according to the records registered in Bushehr province's blood transfusion organization were studied. Donors had been passed the initial screening (ELISA) and confirmatory test (Western Blot) for HIV Ags.

\section{Results}

A total of 51884 people out of 66873 volunteers were able to blood sampled. 24 of them were HIV positive with respect to initial screening test. The results verified in confirmatory test for 6 donors (Prevalence $=0.011 \%$ ). All of them were undergraduate men, below diploma, 4 married and 2 singles and all younger than 35 years old except one. It is notable that 5 people out of 24 people who were HIV positive with respect to initial screening test, were self-rejected their bloods out of the cycle secretly and confirmatory test were also positive for these 5 individuals. (Self reject $=83.33 \%$ ).

\section{Discussion}

HIV-contaminated bloods make a few percentage of all donated bloods. These contaminated bloods mostly belong to undergraduate young men whom don't belong to high social levels. At the same time, due to awareness of their high-risk behavior they don't want their blood to be injected to others. According to this fact that most of infected persons were young and undergraduate married men, this segment of society should be more considered.

\section{Author details}

'Bushehr University of Medical Sciences - Student's Research Committee, Bushehr, Iran, Islamic Republic of. ${ }^{2}$ Bushehr Blood transfusion organization, Bushehr, Iran, Islamic Republic of.

Published: 11 May 2010

\section{doi:10.1186/1742-4690-7-S1-P119}

Cite this article as: Maneshi et al:: Human immunodeficiency virus viral markers seroperevalence in first-time healthy blood donors refered to transfusion centers of bushehr province, South of Iran (April 2004 to March 2008). Retrovirology 2010 7(Suppl 1):P119.

* Correspondence: $\mathrm{h}$ maneshi@yahoo.com

${ }^{1}$ Bushehr University of Medical Sciences - Student's Research Committee, Bushehr, Iran, Islamic Republic of 